\title{
Arsenicosis, possibly from contaminated groundwater, associated with non- cirrhotic intrahepatic portal hypertension
}

\author{
Ashish Goel $^{1}$, Pamela Christudoss ${ }^{2}$, Renu George ${ }^{3}$, Banumathi Ramakrishna ${ }^{4}$, G. Jayakumar Amirtharaj ${ }^{5}$, \\ Shyamkumar N. Keshava ${ }^{6}$, Anup Ramachandran ${ }^{5}$, KA Balasubramanian ${ }^{5}$, Ian Mackie ${ }^{7}$, Jude J. Fleming ${ }^{2}$, Elwyn \\ Elias $^{1,8}$, Chundamannil.E.Eapen ${ }^{1}$ \\ Departments of Hepatology ${ }^{1}$, Clinical Biochemistry ${ }^{2}$, Dermatology ${ }^{3}$, Pathology ${ }^{4}$, Wellcome Trust Research \\ Laboratory $^{5}$, and Radiology ${ }^{6}$, Christian Medical College, Vellore, India; Haemostasis Research Unit, Haematology \\ Department, \\ University College London, London, $\mathrm{UK}^{7}$, University Hospital Birmingham, Birmingham, $\mathrm{UK}^{8}$.
}

\begin{abstract}
:
Background and Aims: Few decades ago, idiopathic non-cirrhotic intrahepatic portal hypertension (NCIPH), a chronic microangiopathy of the liver, caused by arsenicosis from use of contaminated groundwater was reported from Asia. This study aimed to see, if in the $21^{\text {st }}$ century, arsenicosis was present in NCIPH patients at our hospital and, if present, to look for groundwater contamination by arsenic in their residential locality.
\end{abstract}

Methods: 27 liver biopsy proven NCIPH patients, 25 portal hypertensive controls with hepatitis B or C related cirrhosis and 25 healthy controls, matched for residential locality, were studied. $84 \%-96 \%$ of study subjects belonged to middle or lower socio-economic category. Arsenicosis was looked for by estimation of arsenic levels in finger / toe nails and by skin examination. Arsenic levels in nails and in ground water (in NCIPH patients with arsenicosis) was estimated by mass spectrometry.

Results : Nail arsenic levels were raised in $5(10 \%)$ portal hypertensive study subjects [2 NCIPH patients (both had skin arsenicosis) and 3 portal hypertensive controls]. All these 5 patients were residents of West Bengal or Bangladesh. Skin arsenicosis was noted in 3 NCIPH patients (11\%) compared to none of disease / healthy controls. Ground water from residential locality of 1 NCIPH patient with arsenicosis (from Bangladesh) showed extremely high level of arsenic (79.5 $\mu \mathrm{g} / \mathrm{L})$. 
Conclusions: Arsenicosis and microangiopathy of liver, possibly caused by environmental contamination continues in parts of Asia. Further studies are needed to understand the mechanisms of such 'poverty-linked thrombophilia'.

Keywords : microangiopathy, endothelial activation, non-cirrhotic portal fibrosis, liver

\section{Introduction}

Idiopathic non-cirrhotic intrahepatic portal hypertension (NCIPH) is an important cause of portal hypertension at our centre $[1,2]$. Non-cirrhotic portal fibrosis is a histological sub-type of the clinical entity, NCIPH, described more commonly in India [3-6].

NCIPH is characterised by a chronic microangiopathy of small intrahepatic portal vein radicles, suggesting that gut derived insults may be driving this disease [7]. We have reported higher prevalence of gut disorders in NCIPH patients in UK and in India (celiac disease in 14\% - 16\% of patients, ulcerative colitis in 9\%) [8,9]. We have also documented low levels of plasma ADAMTS13 \{ a disintegrin and metalloproteinase with thrombospondin type 1 motif, member 13; a von Willebrand factor (vWF) cleaving protease\}, despite well-compensated liver functions, and raised plasma vWF levels in NCIPH patients. ADAMTS13 to vWF imbalance may predispose to platelet-microthrombi formation in portal venules in response to gut derived insults - thus providing a mechanistic explanation for development of the isolated intrahepatic portal microangiopathy of NCIPH $[10,11]$.

Chronic arsenic ingestion, from contaminated groundwater [12], provides yet another example of gut derived insult driving NCIPH reported from various parts of India 1 - 5 decades ago [13-16]. At biopsy, hepatic arsenic content was higher in patients with NCIPH than in those with cirrhosis [13]. In 1988, investigators from W. Bengal reported 13 cases with non-cirrhotic portal fibrosis which were associated to drinking of water contaminated with arsenic and also associated with 
high level of arsenic in liver tissue [16]. In a murine model, chronic arsenic ingestion caused significant hepatic fibrosis [17]. In contrast, from the West, arsenicosis causing NCIPH has been secondary to use of arsenic preparation (oral Fowler's solution) to treat psoriasis [18-20].

We conducted this study to look for evidence of chronic arsenic toxicity in NCIPH patients and for evidence of groundwater arsenic contamination causing the same, in present day Indian subcontinent.

\section{Materials and Methods :}

This hospital based case-control study was done to evaluate the association of arsenicosis with NCIPH. We compared patients with NCIPH (cases) to patients with hepatitis $\mathrm{B} / \mathrm{C}$ related cirrhosis with portal hypertension (disease controls) and healthy controls. The study subjects were recruited after obtaining their informed consent for the study.

\section{Recruitment of NCIPH cases and controls}

NCIPH was diagnosed as per published criteria [21], as follows: All NCIPH patients had esophageal or gastric varices (on endoscopy) with patent portal vein and hepatic venous outflow tract on Doppler ultrasound and an unyielding detailed clinical and laboratory evaluation for known etiologies of cirrhosis. All cases underwent liver biopsy which showed absence of advanced fibrosis / cirrhosis and of histological process suggesting alternate etiology, e.g. autoimmune hepatitis etc. None of the cases had any disease known to histopathologically mimic NCIPH e.g. sarcoidosis, schistosomiasis etc [21].

27 consecutive NCIPH patients were recruited for the study. The route of liver biopsy in NCIPH cases (transjugular : 18; percutaneous : 6; per-operative : 3) was decided by clinician on a caseto-case basis. In 3 patients, tru-cut and wedge biopsies of the liver were obtained during splenorenal shunt surgery. During transjugular liver biopsy, 3 (2-9); median (range) cores of liver with 
size being 11 (4-19) $\mathrm{mm}$ and containing 8 (5-15) portal tracts were obtained. Similarly, during percutaneous liver biopsy 3 (2-3) cores of liver with size being 13 (8-13) $\mathrm{mm}$ and containing 10 (7-20) portal tracts were obtained.

The liver biopsy in these 27 patients with NCIPH showed portal fibrosis, which was mild in 17 and moderate in 2; mild peri-sinusoidal fibrosis (2) and incomplete septal cirrhosis (2). Other liver biopsy findings in NCIPH cases were - mild sinusoidal dilatation (13), portal vein ectasia with extension into parenchyma (8), atretic portal venules (2) and nodular regenerative hyperplasia (1).

Disease controls were consecutively enrolled patients with hepatitis B or C related cirrhosis with portal hypertension, diagnosed as per radiology, laboratory and endoscopy findings. Post liver transplant patients and patients with hepatocellular malignancy were excluded. Patients with acute illness were also excluded from the study. Healthy volunteers served as healthy controls. The controls were residents from similar locality as the cases.

Besides routine clinical evaluation of study subjects, relevant laboratory evaluation was done as per case to case basis. Liver disease severity was assessed by Child's score. As a marker of liver fibrosis, Aspartate aminotransferase to Platelet ratio index (APRI) was calculated [22]. Serum vitamin B12 assay was performed using electrochemiluminescence technique using a Roche E170

modular system. Normal serum vitamin B12 levels are 200-950 pg/ml. Socioeconomic class of study subjects was assessed by modified Kuppuswamy score, utilising Indian consumer price index of August 2011, i.e. 194 [23,24].

\section{Evaluation for arsenicosis}

Nail arsenic level was measured as per the previously described methodology [25]. In brief, clippings from finger and / or toe nails were collected from study subject, stored in labelled polyethylene bags at $4^{\circ} \mathrm{c}$ till tested. After removing the dirt on their surface manually, the nails 
were washed using an ultrasonic bath in distilled water, and then in acetone. Overnight dried nail samples were then digested by microwave and arsenic levels measured by inductively coupled mass spectrometry. Quantitation was achieved by use of internal standards.

Normal nail arsenic levels are $0.02-0.5 \mathrm{mg} / \mathrm{kg}$ of nail. Arsenic levels of $>1.5 \mathrm{mg} / \mathrm{kg}$ of nail were considered high and indicative of over-exposure to arsenic in the recent past (9 months) [26].

All study cases underwent a thorough dermatological assessment for skin changes suggesting arsenicosis by a single dermatologist (R.G.), who was blinded to the nail arsenic levels. Skin arsenicosis was defined as typical skin lesions - hyperpigmentation and/or hypopigmentation of the unexposed body parts and/or keratosis of the palms/soles [26].

Evaluation for thrombocytopenia associated with ADAMTS13-vWF imbalance in NCIPH patients with arsenicosis

In NCIPH patients with arsenicosis, we assessed platelet counts, plasma activity of ADAMTS13 and of vWF. ADAMTS13 activity was estimated in citrated platelet-poor plasma by an in-house collagen binding assay as previously described [11,27,28]. vWF activity by collagen binding was estimated in citrated plasma by a commercially available ELISA (Hyphen- biomed \#RK038A, France). Normal plasma ADAMTS13 activity was 55-160\% and normal plasma vWF activity was 50-150\%. vWF:ADAMTS13 ratio was calculated. A ratio of $\geq 3$ was considered as suggesting ADAMTS13-vWF imbalance.

\section{Statistical analysis}

All discrete variables are reported as numbers (percentage) and continuous variables as median (range). Non-parametric tests were used for comparison and a p-value of $<0.05$ was considered as significant. The study was approved by institutional review board and ethics committee.

\section{Results}


During August 2011 - August 2013, consecutive patients attending the out-patient liver clinic fulfilling the inclusion and exclusion criteria were recruited for the study. 27 NCIPH cases and 25 portal hypertensive disease controls (hepatitis B related cirrhosis : 21; hepatitis C cirrhosis : 4) and 25 healthy controls were recruited. Demographic data of the 3 groups is depicted in table 1 .

Majority of participants in all the 3 groups were from eastern India. Most study subjects belonged to middle and lower socioeconomic class. The monthly family income for the NCIPH cases was Rs. 10,000; Rs. 3000-Rs. 40000 (median; range), for healthy controls was Rs. 3000; Rs. 1000-Rs. 25000) and for disease controls was Rs. 10,000; Rs. 2000Rs. 30000. On interview, none of the study subjects resided next to a mining area or were on long term complementary medications.

\section{Baseline liver disease status in study subjects :}

Table 2 depicts the severity of liver disease and portal hypertension in cases and disease controls. Platelet counts were similar in both the groups. Platelet counts were normal in 1 case and in 3 disease controls. There was mild-moderate thrombocytopenia $(>50000 / \mathrm{cmm})$ in 12 cases and 13 disease controls and severe thrombocytopenia $(<50000 / \mathrm{cmm})$ in 14 cases and 9 disease controls. Liver disease was more severe in disease controls as compared to cases. Of the $8 \mathrm{NCIPH}$ patients evaluated for vWFADAMTS13 balance, 4 patients had low ADAMTS13 activity $(<55 \%), 6$ patients had high vWF activity ( $>150 \%)$ and 6 patients had vWF:ADAMTS13 ratio of $>3$. Low serum vitamin B12 levels were noted in $5(19 \%)$ NCIPH cases as compared to nil disease control patients tested.

\section{Arsenic levels in nails :}


Arsenic levels in nail clippings in cases $(0.12,0.023-2.24 \mathrm{mg} / \mathrm{kg}$; median, range) were similar to that in disease controls $(0.15,0.01-0.64$; p-value : 0.67$)$ and in healthy controls (0.1, 0.02-0.39; p-value : 0.74) (Figure 1).

Arsenic levels in the nail did not correlate with platelet count, APRI, Child's score and HVPG in NCIPH and disease controls (data not shown).

Two NCIPH patients (both from West Bengal) and 3 disease controls (all from Bangladesh) had raised (i.e. $>0.5 \mathrm{mg} / \mathrm{kg}$ of nail) nail arsenic levels. One NCIPH patient, compared to none in both the control groups, had nail arsenic level of $>1.5 \mathrm{mg} / \mathrm{kg}$.

\section{Skin changes of arsenicosis :}

Three patients with NCIPH had skin changes suggesting arsenicosis (Figure 2) as compared to none amongst the disease controls nor in healthy controls ( $p$-value : 0.2 ), Table 3. These patients had predominant patchy hypo/ hyper pigmentation on the trunk and punctuate keratosis involving mainly the palms. One patient had extensive keratosis involving the feet as well. None of these patients had any feature suggesting psoriasis. Nail arsenic levels in these 3 patients with skin arsenicosis were $0.23,0.8$ and $2.24 \mathrm{mg} / \mathrm{kg}$ of nail.

\section{Details of patients with arsenicosis :}

The 3 NCIPH cases with arsenicosis belonged to Bangladesh $(n=1)$ and West Bengal $(n=2)$. All 3 patients were males with age of 46 (40-54) years. One patient presented with hematemesis (managed endoscopically) and the other 2 patients presented with splenomegaly and hypersplenism (managed conservatively). All 3 patients were in Child's class A at presentation. There was no family history of similar disease in these 
patients. The duration of symptoms prior to presentation to our centre in these 3 patients were 24 (12-36) months.

The liver biopsy in these 3 patients (transjugular : 2; percutaneous : 1) showed mild portal fibrosis (2), mild sinusoidal dilation (2) and ectatic portal vein radicles (1) (Figure 3). HVPG measured in 1 patient was $7 \mathrm{~mm} \mathrm{Hg}$. They remain well with a follow up of 37 (3458) months (from time of initial presentation to our centre).

The 3 NCIPH patients with arsenicosis were similar to the NCIPH patients without skin arsenicosis in their presentation, severity of liver disease and portal hypertension (HVPG and APRI) at presentation. The nail arsenic levels, on the other hand, were elevated in patients with skin arsenicosis (Table 4).

In the 2 NCIPH patients with skin arsenicosis tested, plasma ADAMTS13 activity was reduced in 1 patient and normal in the other $(46 \%, 66 \%)$, while plasma vWF activity was increased in both patients $(393 \%, 257 \%)$. vWF:ADAMTS13 ratio in these two patients was $8.54,3.89$ respectively.

\section{Analysis of groundwater for arsenic contamination :}

Two NCIPH patients with arsenicosis brought groundwater samples obtained from wells (used for drinking water) their local residential locality. The assay for arsenic levels in these samples showed $79.5 \mu \mathrm{g} / \mathrm{L}$ (patient from Jessore, Bangladesh, with nail arsenic level of $0.23 \mathrm{mg} / \mathrm{kg}$ of nail), and $0.9 \mu \mathrm{g} / \mathrm{L}$ (patient from Murshidabad, West Bengal with nail arsenic level of $0.8 \mathrm{mg} / \mathrm{kg}$ of nail), Thus, in 1 patient from Bangladesh, the arsenic level in drinking water was much higher than the WHO guideline of $<10 \mu \mathrm{g} / \mathrm{L}$ and also the Indian standard of $<50 \mu \mathrm{g} / \mathrm{L}$. All the 3 patients with arsenicosis were counselled about 
the possible drinking water contamination with arsenic and about steps needed to rectify this.

\section{Other associated disorders in patients with $\mathrm{NCIPH}$ :}

The other associated disorders in patients with NCIPH were - adult celiac disease $(n=3$; male : 2; age : 29, 28-37 years; median, range) and systemic lupus erythematosus $(n=1$; age : 31 year, female). In addition, one patient had history of pre-eclampsia during prior pregnancy. One patient developed glomerulonephritis 10 years after distal spleno-renal shunt surgery.

\section{Discussion}

In this study, we demonstrate clinical (dermatological) evidence of arsenicosis was present in $11 \%$ ( 3 of 27) of NCIPH patients studied, increased nail arsenic levels in $10 \%$ (5 of 52) portal hypertensive study patients ( 2 NCIPH and 3 disease controls, all residents of West Bengal or Bangladesh which are plains fed by the Himalayan rivers - Ganges and Brahmaputra) and arsenic contamination of groundwater in the residential locality of 1 NCIPH patient with arsenicosis (from Bangladesh). Our report suggests continued environmental contamination as possible cause of arsenicosis associated with portal hypertension in the second decade of the $21^{\text {st }}$ century - reported previously from the Indian subcontinent $10-50$ years ago [12-16].

We hypothesize that in a predisposed individual, chronic ingestion of arsenic may lead to occlusion of the intrahepatic small branches of portal venules, as is characteristic of NCIPH [29]. In our study, histological evidence supporting portal microangiopathy was 
noted in liver biopsy in the 27 NCIPH patients in the form of sinusoidal dilatation, abnormal dilatation of portal venules, atretic portal venules and nodular regenerative hyperplasia. In our previous studies, we have documented low ADAMTS13 as a possible predisposition for development of NCIPH $[10,11]$. It is possible that NCIPH, an example of an isolated microangiopathy affecting the liver is caused by endothelial dysfunction (low ADAMTS13 levels and high vWF levels) which can accentuate platelet adhesion to endothelium, and small vessel occlusion inside the liver by platelet microthrombi [7]. In the present report, vWF-ADAMTS13 imbalance associated with thrombocytopenia was noted in 6 of the 8 NCIPH patients tested including the 2 NCIPH patients with arsenicosis (Child's score of 5 and 6). Multiple animal studies have implicated the role of oxidative stress, activation of hepatic stellate cells, enhanced apoptosis of the hepatocytes and consequent collagen deposition in arsenic induced damage of the liver [30-33]. Arsenic also activates endothelium and increases vWF antigen expression on endothelial cells in vitro [34]. Mechanism of arsenic induced damage in mouse liver can be indirect by endothelial stimulation, rather than by direct cell damage [35]. We have not tested for other prothrombotic disorders in the study subjects, this is a limitation of our study.

We have observed histological evidence of NCIPH characterized by evidence of liver fibrosis/ sinusoidal dilation in three portal hypertensive patients with arsenicosis diagnosed by presence of typical arsenical skin lesion [26]. Majority (90\%) of NCIPH in the current study did not have arsenicosis, clearly indicating that multiple agents can contribute to causation of NCIPH. In our study, there was no difference in liver biopsy findings and clinical presentation of NCIPH patients with or without arsenicosis.

In our study, the proportion of patients with increased nail arsenic was similar among NCIPH cases and in disease controls (with hepatitis B / C related cirrhosis and portal 
hypertension) (Table 3). This suggests that arsenicosis could be a co-factor in pathogenesis (for example by causing intrahepatic endothelial activation leading to platelet plugging of small blood vessels in the liver) of NCIPH as well as of other causes of portal hypertension. Wanless et al [36], proposed that intrahepatic microvenular occlusion contributes to development and progression of cirrhosis [36]. Whether chronic arsenic exposure can accelerate this process in patients with cirrhosis of different etiologies remains to be studied.

As per WHO criteria, we have defined arsenicosis as the presence of typical skin manifestations [26]. None of the patients had any other extra-hepatic manifestations of arsenicosis like respiratory symptoms or neuropathy. Nail arsenic levels reflect exposure to arsenic over previous 3-9 months and thus may only be helpful in ongoing chronic exposure. This may not necessarily exclude chronic exposure only in the remote past [26]. In acute arsenic poisoning, urinary arsenic level gives the clue to recent ingestion of arsenic [37].

It is likely that chronic arsenic exposure by drinking contaminated groundwater is the cause of arsenicosis in our study patients. Analysis of groundwater for arsenic levels was performed in only 2 patients with NCIPH and arsenicosis and not in all other study patients (this is a limitation of our study).

There are reports of increased metallic impurities, including arsenic, in complementary medicines $[38,39]$. None of our study patients gave a history of long-term intake of these medications.

Groundwater contamination by arsenic in south and south-east Asia is well documented in Bangladesh, Eastern India (delta regions of Ganges, Brahmaputra) and Cambodia, 
Vietnam (Mekong delta). Arsenic leached out from sediments in Himalayan Mountains into river water undergoes microbial reduction in anaerobic conditions [40]. Public health measures in place to combat this are - identifying and marking contaminated source, shifting to safe source of water wherever possible (e.g. adequately treated surface water, rain water harvesting or alternate ground water source, increasing the depth of the well etc.), continuous education / participation of the community and use of arsenic treatment plants/ filters $[41,42]$. As seen in our study, people from the poorer strata of society are still vulnerable to the effects of this environmental contamination (Figure 2, Table 4). Ongoing arsenicosis in West Bengal and Bangladesh documented in this present report indicates the need to strengthen public health measures further. The 'Clean Ganges' project initiative of the Government of India, is likely to reduce environmental contamination in the Gangetic plains [43].

It is postulated that genetic and environmental factors predispose to development of NCIPH [7]. In the past decade, few centres in India have reported decreasing incidence of NCIPH [4,5], this may reflect changing environmental factors in disease causation. Better sanitation and increasing use of bottled mineral water for drinking maybe some reasons for reduction of NCIPH in some parts of India. The current report on arsenicosis associated with NCIPH in patients living in areas fed by arsenic contaminated waters of Ganges - Brahmaputra rivers provides an explanation to why NCIPH is so common in India, a question asked by Professor Okuda many years ago [3].

NCIPH is reported in patients belonging to poorer socio-economic strata [1]. Majority $(84 \%-96 \%)$ of study subjects in this study belonged to middle or lower socio-economic category. We have previously reported utility of low serum vitamin B12 level as a non invasive marker of NCIPH [44], vitamin B12 deficiency was seen in 19\% of NCIPH and 
in none of the disease controls tested. Further studies are needed to see if vitamin B12 deficiency contributes to causation of NCIPH.

In conclusion, we demonstrate that NCIPH associated with arsenicosis, possibly from contaminated groundwater, is an on-going problem in the Indian subcontinent in the $21^{\text {st }}$ century. Environmental contamination causing chronic arsenicosis and NCIPH in West Bengal, India and in Bangladesh maybe considered an example of "poverty-linked thrombophilia' causing chronic microangiopathy in the liver.

\section{Compliance with ethical standards}

Conflict of interest: AG, PC, RG, BR, GJA, SNK, RA, KAB, IM, JJF, EE, CEE confirm that they have no conflicts of interest to declare.

Ethics statement The study was performed in a manner to conform with the Helsinki Declaration of 1975, as revised in 2000 and 2008 concerning human and animal rights, and the authors followed the policy concerning informed consent as shown on Springer.com.

Financial support : We gratefully acknowledge funds received from Department of Science and Technology, Government of India (EMR/2015/000570) and fluid research funds, Christian Medical College, Vellore, India towards conduct of this study.

\section{References}


[1] Goel A, Madhu K, Zachariah U et al. A study of aetiology of portal hypertension in adults (including the elderly) at a tertiary centre in southern India. Indian J Med Res 2013;137:922-7.

[2] Madhu K, Avinash B, Ramakrishna B et al. Idiopathic non-cirrhotic intrahepatic portal hypertension: common cause of cryptogenic intrahepatic portal hypertension in a Southern Indian tertiary hospital. Indian J Gastroenterol $2009 ; 28: 83-7$.

[3] Okuda K. Non-cirrhotic portal hypertension: why is it so common in India? J Gastroenterol Hepatol. 2002;17:1-5.

[4] Chawla Y, Duseja A. Non-cirrhotic portal fibrosis (NCPF) is a vanishing disease in India. Trop Gastroenterol 2003;24:45-6.

[5] Sarin SK, Kumar A, Chawla YK et al. Non-cirrhotic portal fibrosis/ idiopathic portal hypertension: APASL recommendations for diagnosis and treatment. Hepatol Int. 2007;1:398-413.

[6] Schouten JN, Garcia-Pagan JC, Valla DC, Janssen HL. Idiopathic noncirrhotic portal hypertension. Hepatology 2011;54:1071-81

[7] Goel A, Elias JE, Eapen CE, Ramakrishna B, Elias E. Idiopathic Non-Cirrhotic Intrahepatic Portal Hypertension (NCIPH)-Newer Insights into Pathogenesis and Emerging Newer Treatment Options. J Clin Exp Hepatol 2014;4:247-56.

[8] Maiwall R, Goel A, Pulimood AB et al. Investigation into celiac disease in Indian patients with portal hypertension. Indian J Gastroenterol 2014;33:517-23.

[9] Eapen CE, Nightingale P, Hubscher SG et al. Non-cirrhotic intrahepatic portal hypertension: associated gut diseases and prognostic factors. Dig Dis Sci 2011;56:227-35. 
[10] Goel A, Alagammai PL, Nair SC et al. ADAMTS13 deficiency, despite well-compensated liver functions in patients with noncirrhotic portal hypertension. Indian J Gastroenterol 2014;33:355-63.

Mackie I, Eapen CE, Neil D et al. Idiopathic noncirrhotic intrahepatic portal hypertension is associated with sustained ADAMTS13 Deficiency. Dig Dis Sci 2011;56:2456-65.

[12] Das D, Chatterjee A, Mandal BK, Samanta G, Chakraborti D, Chanda B. Arsenic in ground water in six districts of West Bengal, India: the biggest arsenic calamity in the world. Part 2. Arsenic concentration in drinking water, hair, nails, urine, skin-scale and liver tissue (biopsy) of the affected people. Analyst 1995;120:917-24.

[13] Santra A, Das Gupta J, De BK, Roy B, Guha Mazumder DN. Hepatic manifestations in chronic arsenic toxicity. Indian J Gastroenterol 1999;18:152-5.

[14] Datta DV. Letter: Arsenic and non-cirrhotic portal hypertension. Lancet $1976 ; 1: 433$.

[15] Datta DV, Mitra SK, Chhuttani PN, Chakravarti RN. Chronic oral arsenic intoxication as a possible aetiological factor in idiopathic portal hypertension (non-cirrhotic portal fibrosis) in India. Gut 1979;20:378-84.

[16] Guha Mazumder DN, Chakraborty AK, Ghose A et al. Chronic arsenic toxicity from drinking tube well water in rural West Bengal. Bull World Health Organ 1988;66:499-506

[17] Sarin SK, Sharma G, Banerjee S, Kathayat R, Malhotra V. Hepatic fibrogenesis using chronic arsenic ingestion: studies in a murine model. Indian J Exp Biol 1999;37:147-51. 
[18] Nevens F, Fevery J, Van Steenbergen W, Sciot R, Desmet V, De Groote J. Arsenic and non-cirrhotic portal hypertension. A report of eight cases. J Hepatol 1990;11:80-5.

[19] Morris JS, Schmid M, Newman S, Scheuer PJ, Sherlock S. Arsenic and noncirrhotic portal hypertension. Gastroenterology. 1974;66:86-94.

[20] Huet PM, Guillaume E, Cote J, Légaré A, Lavoie P, Viallet A. Noncirrhotic presinusoidal portal hypertension associated with chronic arsenical intoxication. Gastroenterology. 1975;68:1270-7.

[21] Hillaire $\mathrm{S}$, Bonte $\mathrm{E}$, Denninger $\mathrm{MH}$ et al. Idiopathic non-cirrhotic intrahepatic portal hypertension in the West: a re-evaluation in 28 patients. Gut 2002;51:275-80.

[22] Toniutto P, Fabris C, Bitetto D et al. Role of AST to platelet ratio index in the detection of liver fibrosis in patients with recurrent hepatitis $\mathrm{C}$ after liver transplantation. J Gastroenterol Hepatol 2007;22:1904-8.

[23] Patro BK, Jeyashree K, Gupta PK. Kuppuswamy's socioeconomic status scale 2010-the need for periodic revision. Indian J Pediatr 2012;79:395-6.

[24] Labour Bureau Statistics: Labour Bureau, Government of India. http://labourbureau.nic.in/indtab.html. Accessed on $15^{\text {th }}$ May 2015.

[25] Samanta G, Sharma R, Roychowdhury T, Chakraborti D. Arsenic and other elements in hair, nails, and skin-scales of arsenic victims in West Bengal, India. Sci Total Environ 2004;326:33-47.

[26] WHO, A field guide for detection, management and surveillance of arsenicosis cases. Caussy D, editor. Technical Publication No 30. New Delhi: WHO, SEARO; 2005. p.11 

von Willebrand factor (vWF)-cleaving protease based on decreased collagen binding affinity of degraded vWF: a tool for the diagnosis of thrombotic thrombocytopenic purpura (TTP). Thromb Haemost 1999;82:1386-9

[28] Yarranton H, Lawrie AS, Mackie IJ, Pinkoski L, Corash L, Machin SJ. Coagulation factor levels in cryosupernatant prepared from plasma treated with amotosalen hydrochloride (S-59) and ultraviolet A light. Transfusion. $2005 ; 45: 1453-8$

[29] Nakanuma Y, Hoso M, Sasaki M et al. Histopathology of the liver in noncirrhotic portal hypertension of unknown aetiology. Histopathology 1996;28:195204.

[30] Santra A, Maiti A, Das S, Lahiri S, Charkaborty SK, GuhaMazumder DN. Hepatic damage caused by chronic arsenic toxicity in experimental animals. J Toxicol ClinToxicol 2000;38(4):395-405

Das S, Santra A, Lahiri S, GuhaMazumder DN: Implication of oxidative stress and hepatic cytokine (TNF-a and IL-6) response in the pathogenesis of hepatic collagenesis in chronic arsenic toxicity. Toxicology \& Applied Pharmacology 2005;204:18-26. apoptosis in mouse liver is mitochondria dependent and is abrogated by Nacetylcysteine. Toxicology and Applied Pharmacology 2007; 220:146-155.

[33] Ghatak S, Biswas A, Dhali GK, Chowdhury A, Boyer JL, Santra A. Oxidative stress and hepatic stellate cell activation are key events in arsenic 
induced liver fibrosis in mice. Toxicology and Applied Pharmacology 2011; 251:59-69.

[34] Kao YH, Yu CL, Chang LW, Yu HS. Low concentrations of arsenic induce vascular endothelial growth factor and nitric oxide release and stimulate angiogenesis in vitro. Chem Res Toxicol 2003;16:460-8.

[35] Straub AC, Stolz DB, Ross MA et al. Arsenic stimulates sinusoidal endothelial cell capillarization and vessel remodelling in mouse liver. Hepatology 2007;45:205-12.

[36] Wanless IR, Wong F, Blendis LM, Greig P, Heathcote EJ, Levy G. Hepatic and portal vein thrombosis in cirrhosis: possible role in development of parenchymal extinction and portal hypertension. Hepatology 1995;21:1238-47.

[37] Ratnaike RN. Acute and chronic arsenic toxicity. Postgrad Med J. 2003 Jul;79(933): 391-6.

[38] Kumar G, Gupta YK. Monitoring of mercury, arsenic, cadmium and lead in Ayurvedic formulations marketed in Delhi by flame AAS and confirmation by ICP-MS. Food Addit Contam Part B Surveill 2012;5:140-4.

[39] Saper RB, Phillips RS, Sehgal A et al. Lead, mercury, and arsenic in USand Indian-manufactured Ayurvedic medicines sold via the Internet. JAMA 2008;300:915-23.

[40] Polizzotto ML, Kocar BD, Benner SG, Sampson M, Fendorf S. Nearsurface wetland sediments as a source of arsenic release to ground water in Asia. Nature 2008; 454, 505-508

[41] Srivastava KK, Chattopadhyay AK, Mehta BC. Technology options for utilisation of arsenic contaminated ground water. Bhu-Jal News (Central Ground 
Water Board, Ministry of Water Resources, Govt. Of India) 2009; Vol 24; 119. http://www.cgwb.gov.in/documents/Bhujal_News_24_2.pdf $\left(\right.$ accessed on $2^{\text {nd }}$ May, 2015)

[42] Ghosh NC, Singh RD. Groundwater Arsenic contamination in IndiaVulnerability and scope for remedy. Central Ground Water Board, Ministry of Water $\quad$ Resources, $\quad$ Govt. $\quad$ Of http://www.cgwb.gov.in/documents/papers/incidpapers/Paper\%208\%20\%20Ghosh.pdf (accessed on $2^{\text {nd }}$ may 2015)

[43] Ministry of Water Resources, River Development \& Ganga Rejuvenation, Government of India. National Mission for Clean Ganga. https://nmcg.nic.in/index.aspx (accessed on $16^{\text {th }}$ June 2015)

[44] Goel A, Ramakrishna B, Muliyil J et al. Use of serum vitamin B12 level as a marker to differentiate idiopathic noncirrhotic intrahepatic portal hypertension from cryptogenic cirrhosis. Dig Dis Sci 2013;58:179-87. 


\section{Figure legends}

Figure 1 : Arsenic level, as measured by inductively coupled mass spectroscopy, in nail compared in the various study groups. The nail arsenic levels in three NCIPH patients with skin arsenicosis are marked with asterisk (*).

Figure 2 : Typical skin changes of arsenicosis (punctuate keratosis (red asterisk *) of the palms) (Panel A) and liver biopsy depicting portal tracts with abnormally dilated portal venules ( Haematoxylin-Eosin10x; Panel B) in 46 year old male with noncirrhotic intrahepatic portal hypertension. He had raised nail arsenic level $(0.8 \mathrm{mg} / \mathrm{kg})$ and his Child's score was 6, with platelet count : 60,000/cmm. He is a resident of West Bengal (India) and belongs to lower socioeconomic category (monthly family income Rs. 3000/-). 
Table 1 : Demographic details of study patients

\begin{tabular}{|c|c|c|c|c|}
\hline \multicolumn{2}{|l|}{ Parameter } & $\begin{array}{c}\text { NCIPH } \\
(n=27)\end{array}$ & $\begin{array}{c}\text { Hepatitis } \\
\text { B/C } \\
\text { cirrhosis } \\
(n=25)\end{array}$ & $\begin{array}{c}\text { Healthy } \\
\text { controls } \\
(\mathbf{n}=25)\end{array}$ \\
\hline \multicolumn{2}{|l|}{ Age (years) } & $\begin{array}{c}35(15- \\
64)\end{array}$ & $36(17-56)$ & $\begin{array}{c}40(20- \\
77)\end{array}$ \\
\hline \multicolumn{2}{|l|}{ Sex } & 19:8 & $23: 2$ & $17: 8$ \\
\hline \multirow{3}{*}{$\begin{array}{l}\text { States of } \\
\text { residence }\end{array}$} & West Bengal / Bangladesh & $7 / 3$ & $7 / 13$ & $13 / 1$ \\
\hline & Bihar/Chattisgarh/Jharkhand & 7 & 2 & 3 \\
\hline & Other states of India & 8 & 3 & 8 \\
\hline \multirow{3}{*}{$\begin{array}{l}\text { Socioeconomic } \\
\text { class* }\end{array}$} & Upper & $4(16 \%)$ & $1(4 \%)$ & $1(8 \%)$ \\
\hline & Middle & $\begin{array}{c}16 \\
(64 \%)\end{array}$ & $19(83 \%)$ & $4(31 \%)$ \\
\hline & Lower & $5(20 \%)$ & $3(13 \%)$ & $8(61 \%)$ \\
\hline
\end{tabular}

NCIPH : Idiopathic non-cirrhotic intrahepatic portal hypertension

*Socioeconomic class data available in 25 cases, 23 disease controls and 13 healthy controls. 
Table 2 : Baseline laboratory assessment of liver disease in patients with portal hypertension (27 cases with NCIPH and 25 patients with hepatitis B/C related cirrhosis)

\begin{tabular}{|c|c|c|c|}
\hline Parameters & $\begin{array}{c}\text { NCIPH } \\
(n=27)\end{array}$ & $\begin{array}{c}\text { Hepatitis B/C } \\
\text { cirrhosis } \\
(n=25)\end{array}$ & $\begin{array}{c}\text { p- } \\
\text { value }\end{array}$ \\
\hline Haemoglobin (g/dl) & $12.3(6.8-15.1)$ & $12.7(8.8-14.6)$ & 0.4 \\
\hline Platelet count $(\mathbf{x 1 0} / \mathrm{cmm})$ & $\begin{array}{c}0.49(0.17- \\
1.78)\end{array}$ & $0.65(0.14-1.57)$ & 0.9 \\
\hline Serum bilirubin (mg/dl) & $1.3(0.4-4)$ & $1(0.4-2.9)$ & 0.3 \\
\hline Serum albumin (mg/dl) & $3.9(2.9-5.5)$ & $3.5(2.1-4.7)$ & 0.07 \\
\hline International Normalised Ratio & $1.2(1-1.4)$ & $1.2(1-1.6)$ & 0.005 \\
\hline $\begin{array}{l}\text { Esophageal } \\
\text { (small/large) }\end{array}$ & $4 / 22 *$ & $8 / 17$ & - \\
\hline Child's score & $5(5-6)$ & $5(5-9)$ & 0.002 \\
\hline APRI & $2(0.6-4.7)$ & $2.2(0.5-11.4)$ & 0.3 \\
\hline HVPG (mm Hg) & $7(3-12)$ & - & \\
\hline${\text { Serum vitamin B12 }(\mathrm{pg} / \mathrm{ml})^{\wedge}}$ & $\begin{array}{c}414(107- \\
1128)\end{array}$ & $808(278-1833)$ & 0.001 \\
\hline ADAMTS13 activity $(\%)^{\&}$ & $55.5(39-86)$ & - & - \\
\hline vWF activity $(\%)^{\&}$ & $260(135-484)$ & - & - \\
\hline vWF:ADAMTS13 ratio $^{\&}$ & $4.1(2.3-8.5)$ & - & - \\
\hline
\end{tabular}

NCIPH : Idiopathic non-cirrhotic intrahepatic portal hypertension, APRI : Aspartate aminotransferase to Platelet ratio index, HVPG : Hepatic venous pressure gradient; ADAMTS13: a disintegrin and metalloproteinase with thrombospondin type 1 motif, member 13; vWF: von-Willebrand factor

*1 patient had no varices, but had spleno-renal collaterals on ultrasonography

${ }^{\#} \mathrm{HVPG}$ was done in $13 \mathrm{NCIPH}$ cases and none of the disease controls. HVPG was $\leq 5$ $\mathrm{mm} \mathrm{Hg}$ in 2 patients and was $>5 \mathrm{~mm} \mathrm{Hg}$ in 11 patients

${ }^{\wedge}$ Serum vitamin B12 assay was available in $26 \mathrm{NCIPH}$ patients and 12 patients with Hepatitis B/C cirrhosis

\&ADAMTS13 and vWF activity was available in 8 NCIPH patients \{Child's score of these 8 patients was 5 (in 7) and 6 (in 1 patient) $\}$ and none of the controls. 
Table 3. Investigations into arsenicosis in study patients

\begin{tabular}{|c|c|c|c|c|}
\hline $\begin{array}{c}\text { Skin changes } \\
\text { of arsenicosis }\end{array}$ & $\begin{array}{c}\text { Nail arsenic } \\
\text { content } \\
(\mathbf{m g} / \mathbf{k g})\end{array}$ & $\begin{array}{c}\text { NCIPH } \\
(\mathbf{n = 2 7})\end{array}$ & $\begin{array}{c}\text { Hepatitis B / C } \\
\text { cirrhosis } \\
(\mathbf{n = 2 5})\end{array}$ & $\begin{array}{c}\text { Healthy } \\
\text { controls } \\
(\mathbf{n = 2 5})\end{array}$ \\
\hline \multirow{3}{*}{ Present } & $\leq 0.5$ & $1^{*}$ & 0 & 0 \\
\cline { 2 - 5 } & $0.5-1.5$ & $1^{\#}$ & 0 & 0 \\
\cline { 2 - 5 } & $\geq 1.5$ & $1^{\#}$ & 0 & 0 \\
\hline \multirow{3}{*}{ Absent } & $\leq 0.5$ & 24 & 22 & 25 \\
\cline { 2 - 6 } & $0.5-1.5$ & 0 & $3^{*}$ & 0 \\
\cline { 2 - 6 } & $\geq 1.5$ & 0 & 0 & 0 \\
\hline
\end{tabular}

NCIPH : Idiopathic non-cirrhotic intrahepatic portal hypertension; Patients from Bangladesh (*) and West Bengal (\#). 
Table 4 : Details of NCIPH patients with / without skin arsenicosis

\begin{tabular}{|l|c|c|l|}
\hline & $\begin{array}{c}\text { NCIPH patients } \\
\text { with skin } \\
\text { arsenicosis } \\
(\mathbf{n = 3})\end{array}$ & $\begin{array}{c}\text { NCIPH patients } \\
\text { without skin } \\
\text { arsenicosis } \\
(\mathbf{n = 2 4})\end{array}$ & $\begin{array}{c}\text { p- } \\
\text { value }\end{array}$ \\
\hline Age (years) & $46(40-54)$ & $33(15-64)$ & 0.016 \\
\hline Male : Female & $3: 0$ & $16: 8$ & 0.5 \\
\hline $\begin{array}{l}\text { From lower socioeconomic } \\
\text { class }\end{array}$ & $2(67 \%)$ & $11(50 \%)$ & 1 \\
\hline $\begin{array}{l}\text { Residents of W. Bengal / } \\
\text { Bangladesh }\end{array}$ & 3 & 7 & 0.02 \\
\hline $\begin{array}{l}\text { Presentation with } \\
\text { hematemesis }\end{array}$ & 1 & 13 & 0.6 \\
\hline Platelet counts (x105/cmm) & $0.6(0.4-0.9)$ & $0.49(0.17-1.8)$ & 0.9 \\
\hline Child's score & $5(5-6)$ & $5(5-6)$ & 0.4 \\
\hline AST - Platelet Ratio Index & $1.1(0.9-2.6)$ & $2.2(0.6-4.7)$ & 0.4 \\
\hline $\begin{array}{l}\text { Moderate portal/peri- } \\
\text { sinusoidal fibrosis on liver } \\
\text { biopsy }\end{array}$ & 0 & 6 & 0.5 \\
\hline Nail Arsenic level ( $\mu$ g/kg) & $0.8(0.2-2.2)$ & $0.1(0.02-0.3)$ & 0.003 \\
\hline $\begin{array}{l}\text { Hepatic venous pressure } \\
\text { gradient (mm Hg)* }\end{array}$ & 7 & $7 \quad(3-12)$ & 1 \\
\hline
\end{tabular}

\#Socioeconomic class data was not available in $2 \mathrm{NCIPH}$ patients without skin arsenciosis

*Hepatic venous pressure gradient available in $1 \mathrm{NCIPH}$ patient with skin arsenicosis and 12 NCIPH patients without skin arsenicosis. 


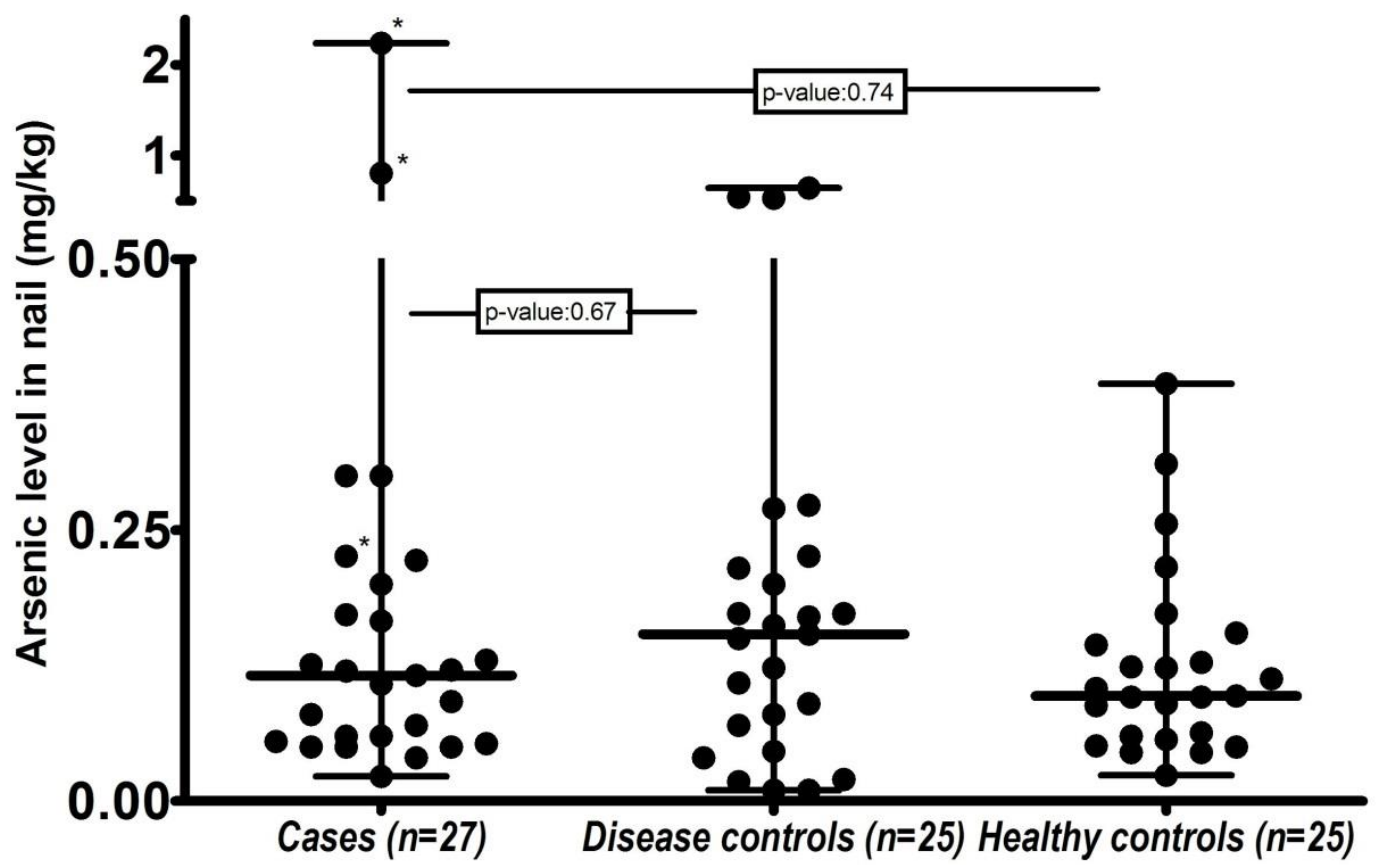

Figure 1 


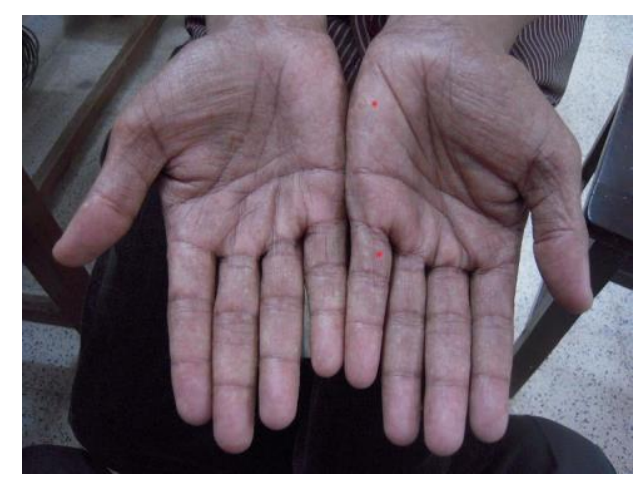

Figure 2a

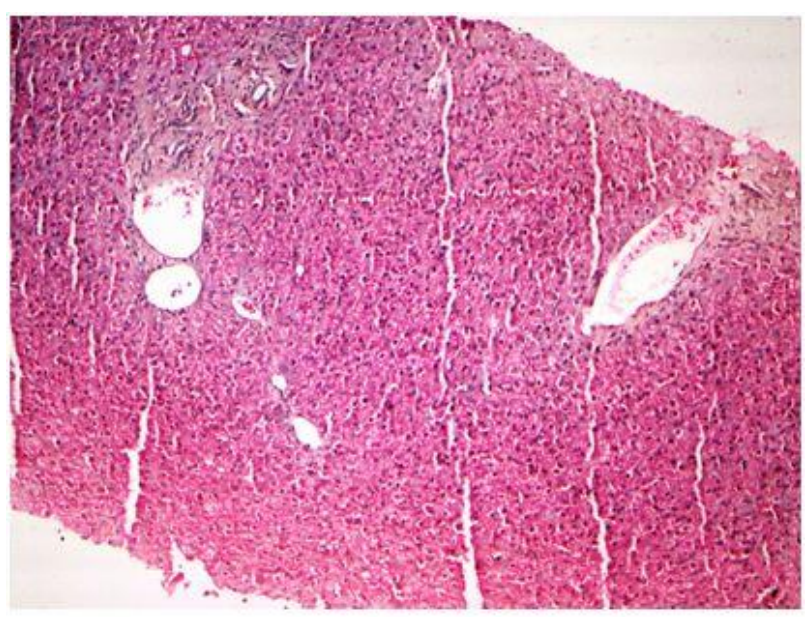

Figure $2 b$ 